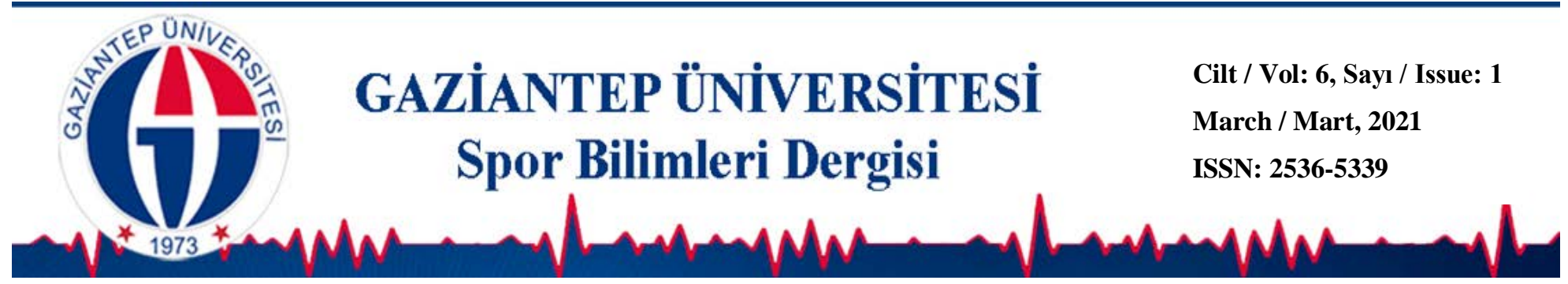

\title{
Tenis Oyuncularında Core Egzersizleri Tenis Performansını Etkiler Mi?
}

\author{
Yasemin $\mathrm{ARI}^{1^{*}}$ \\ Filiz Fatma ÇOLAKOĞLU² \\ ${ }^{1}$ Tekirdağ Namık Kemal Üniversitesi, Beden Eğitimi ve Spor Yüksekokulu, TEKİRDA $\breve{G}$ \\ ${ }^{2}$ Gazi Üniversitesi, Spor Bilimleri Fakültesi, ANKARA
}

DOI: $10.31680 /$ gaunjss.796043

Orijinal Makale / Original Article

Geliş Tarihi / Received: 16.09.2020
Kabul Tarihi / Accepted: 01.02.2021
Yayın Tarihi / Published: 22.03.2021

\section{Öz}

Bu çalışma tenis oyuncularında core egzersiz programının tenis performansına etkilerini araştırmak amacıyla yapıldı. Çalışmaya 13-16 yaş arası toplam 31 erkek tenis oyuncusu gönüllü katıldı. Tenis oyuncuları rastgele 1. grup (deney=16; core egzersiz + tenis teknik antrenman) ve 2. grup (kontrol=15; tenis teknik antrenman) olarak farkı iki gruba ayrılı. Çalışmaya dahil edilen katılımcılar 8 haftalık egzersiz öncesi ve sonrası değerlendirildi. Performans değerlendirmesi için durarak uzun atlama, el kavrama kuvveti, flamingo denge, otur-uzan esneklik ve mekik testi yapıldı. Verilerin normal dağıııma uygunlukları için grafiksel yaklaşımlar ve normallik testlerinden örneklemli 'Shapiro-Wilk' testi yapıldı. İki grup ortalamaları arasındaki tüm parametrelerinin karşılaştırılması için "Independent Sample T Testi" grup içi karşılaştırmalarda zamanın (egzersiz öncesi - sonrası) etkilerini saptamak için tekrarlı değişkenlerin analizinde "Paired Sample T Testi" ile yapıldı. İstatistiksel anlamlılık için eşik değer olarak 0,05-0,01 $\mathrm{p}$ değeri belirlendi. Çalışma sonucunda deney ve kontrol grubunda flamingo denge testinde anlamlı farkılık elde edildi $(p<0,05-p<0,01)$. Core antrenman sonrası deney grubunda durarak uzun atlama, el kavrama kuvveti, otur-uzan esneklik ve mekik parametrelerinde egzersiz sonrası ortalamaları egzersiz öncesine göre anlamlı arış olduğu tespit edildi $(p<0,01)$. Sonuç olarak, core egzersiz programlarının tenis performansına etkisinin olduğu söylenebilir.

Anahtar Kelimeler: Atletik performans, core egzersiz, tenis

\section{Do Core Exercises in Tennis Players Affect Tennis Performance?}

\begin{abstract}
This study was conducted to investigate the effects on tennis performance of the core exercise program in tennis players. To work total of 31 male tennis players aged 13-16 years participated in the study. Tennis players were randomly divided into two different groups as 1 st group (experiment $=16$; core exercise + tennis technical training) and 2nd group (control = 15; tennis technical training). Participants included in the study were evaluated before and after 8 weeks of exercise. For performance evaluation, long jump, hand grip strength, flamingo balance, sit-and-stretch flexibility and shuttle test were performed. For the compatibility of the data to normal distribution was done 'Shapiro-Wilk' test with graphical approaches and normality tests. In order to compare all parameters between the averages of the two groups, "Independent Sample T Test" was performed with "Paired Sample T Test" in the analysis of repetitive variables to determine the effects of time (before and after exercise) in-group comparisons. Threshold value for statistical significance was determined as 0,05-0,01 p. As a result of the study, there was a significant difference in the flamingo balance test in the experimental and control groups $(p<0,05-p<0,01)$. Experimental group after core training was found a significant increase after the exercise compared to pre-exercise in long jump, hand grip strength, sit-and-stretch flexibility and sit-up parameters $(p<0,01)$. As a result, it can be said that core exercise programs have an impact on tennis performance.

Keywords: Athletic performance, core exercise, tennis
\end{abstract}

\footnotetext{
* Sorumlu Yazar: Yasemin ARI
}

e-mail: yaseminari88@gmail.com 


\section{Giriş}

Dünyanın popüler sporlarından biri olan tenis, 75 milyondan fazla kişi tarafından oynanmakta (Pluim ve ark., 2007) ve dünya çapında milyonlarca taraftarı cezbeden, rekabete dayanan bir spordur (Fernandez-Fernandez ve ark., 2013). Bu sporda, zaman sınırlaması olmadığından, müsabakalar 1 saatten az veya 5 saatten fazla sürebilmektedir (Kilit ve Arslan, 2017). Bu nedenle aerobik - anaerobik kapasite, hız, esneklik, çeviklik, denge ve patlayıcı güç yeteneğine ihtiyaç duyulur (Bashir ve ark., 2019). Özellikle tenis maçlarının çok uzun zaman almasından dolayı, müsabaka sonucunu belirleyen en önemli belirteç, sporcuların aerobik kapasitesidir. Aerobik kapasitesi yüksek olan tenis oyuncuları, dengeli ve sürekli vuruş yapmasıyla birlikte, dinlenme aralarında sporcu hemen toparlanarak bir sonraki oyuna hazır olur. (Urhausen ve Kindermann, 2002).

Rakip ile temasın olmadığı tenis sporu, tek boyutlu bir oyun değildir. Oyuncular sürekli olarak kolun çok hızlı hareketleri, hamleleri ve sıçramalarıyla vücudunu topa doğru bir yandan diğer yana, ani yön değiştirerek döndürürler (Samson, 2005). Dolayısıyla teniste daha fazla topa ulaşabilmek, uygun vuruş pozisyonuna hazırlanmak ve gerekli vuruş zamanının olması için, kısa mesafeli patlayıcı koşulara ihtiyaç duyulmaktadır (Gelen ve ark., 2009; Lloyd ve diğerleri, 2013). Aynı zamanda oyun içerisinde el-göz koordinasyonu, top ve raket ile eşgüdüm, ritim ve uyum gerekmektedir (Reid ve ark., 2003).

Tenis, güvenli bir spor olmasına rağmen, artan süresi, yüksek oyun yoğunluğu nedeniyle genç oyuncuların baskı altında oynamalarına ve kendilerini gergin hissetmelerine neden olmaktadır. Özellikle aralıksız üst-alt ekstremite üzerine gelen bu baskı, yaralanma riskini de artırmaktadır (Kermen, 1994). Yaralanma riskini azaltabilmek ve oluşan yaralanmalarla spora hızlı dönüş sağlanabilmesi için core kasları, üst ve alt ekstremiteler arasında bir köprü görevi görmektedir (Sandrey ve Mitzel, 2013). Bu nedenle tenis oyuncuları, üst ve alt ekstremite hareketlerini etkili bir şekilde gerçekleştirebilmek için yüksek core gücüne ihtiyaç duymaktadırlar (Samson ve ark., 2007). Yüksek core gücü, alt ekstremite için en kısa sürede topa vuruş reaksiyonunu sağladığı gibi, üst ekstremite de ise, kuvvetli ve doğru raket tutuşu, vuruş esnasında hızlı vurulmasıyla birlikte, raket dengesinin korunmasını da sağlamaktadır (Bompa ve ark., 2014).

Core, vücudun lumbopelvik bölgesi veya gövde kısmı için kullanılmaktadır (McGill ve ark., 2003; Panjabi, 1992; Sever ve ark., 2017). Sportif performans 
Arı, Y. ve Çolakoğlu, F.F. (2021). Tenis Oyuncularında Core Egzersizleri Tenis Performansını Etkiler Mi? Gaziantep Üniversitesi Spor Bilimleri Dergisi, 6(1), 40-54.

araştırmacıları core terimini, bel, kalça ve karın bölgesine odaklanarak, sternum ve dizler arasındaki tüm anatomiyi dahil ederken (Fig, 2005), diğer araştırmacılar ise, core kas sistemini omuz ve pelvis kaslarını içermesi gerektiğini belirtmişlerdir (Stephenson ve Swank, 2004; Tse ve ark., 2005). Leetun ve ark. (2004) ise kalça kası aktivasyonunun üst bacak kaslarında kuvvet üretme ve direnç gösterme yeteneğini önemli ölçüde etkilediğini, core dengesini ve core gücünü geliştirmeye çalışırken kalça kası aktivasyonunun önemli olduğunu vurgulamışlardır. Wilson (2005) gluteus kaslarının core denge ve kalça kontrolünde önemli bir rolü olduğunu belirtmişlerdir. Araştırmalar, core kaslardaki iyileşmenin çeşitli lomber omurga ve kasiskelet sistemi bozukluklarını önlemenin yanı sıra, atletik performansın arttırımasında da önemli bir rol oynayabileceğini vurgulamışlardır (Akuthota ve Nadler, 2004).

Gür ve Ersöz (2017) tenis sporcularına uygulanan core antrenmanın, gövde kuvveti ve stabilitesi üzerinde sportif performans açısından pozitif etkisi olduğunu belirtmişlerdir. Aynı zamanda core kaslarına yönelik yapılan antrenmanlar, fiziksel uygunluk ve kort üzerindeki hareketlilik bileşenlerini etkileyebilecek, önemli bir unsur olduğunu vurgulamışlardır.

Sever ve ark. (2017), genç tenisçilerde, core antrenman uygulamalarının, isabetli servis hızını, olumlu etkilediğini tespit etmişlerdir. Weston ve ark. (2015) yüzücülere uygulanan core eğitim programından sonra, 50 metrelik yüzme performansı üzerinde, pozitif sonuçlar bulmuşlardır.

Core egzersizlerinin, tenis sporunda gerekli olan motor beceri performansı üzerinde etkisi ile ilgili araştırmaların sınırlı sayıda olduğu görülmüştür. Bu nedenle, tenis oyuncularında tenis performansını geliştirmek için tenis teknik antrenmanı ile birlikte farklı core egzersiz programının uygulanmasının uygun olduğu varsayılmaktadır. Çalışmanın amacı, 8 hafta uygulanan core egzersiz programının tenis performansına etkilerini araştırmaktır.

\section{Yöntem}

\section{Araştırmanın Grubu}

$\mathrm{Bu}$ araştırmaya bilinen herhangi bir sağlık sorunu, alt-üst ekstremiteye ait herhangi bir patolojisi ve deformitesi olmayan, teniste spor yaşı en az 2 yıl olan

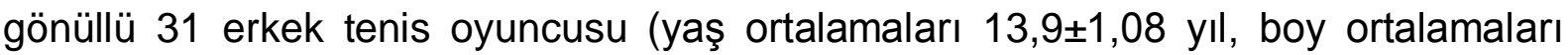

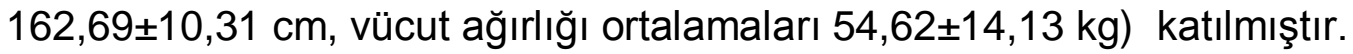


Arı, Y. ve Çolakoğlu, F.F. (2021). Tenis Oyuncularında Core Egzersizleri Tenis Performansını Etkiler Mi? Gaziantep Üniversitesi Spor Bilimleri Dergisi, 6(1), 40-54.

Oyuncular rastgele birinci grup (deney $n=16$ ), core egzersiz + tenis teknik antrenman, ikinci grup (kontrol $\mathrm{n}=15$ ) ise sadece tenis teknik antrenman olarak iki gruba ayrılmışlardır. Her iki grupta da iki antrenman üstünde devamsızlık yapan ve her iki ölçümde yer almayan sporcular çalışma dışı bırakılmışlardır. Araştırma ön ve son teste devam eden sporcular ile analize devam edilmiştir. Çalışma ile ilgili sporculara, velilere ve antrenörlere ayrıntılı bilgi verildi ve araştırmaya gönüllü olarak katıldıklarına dair aydınlatılmış onam formu doldurmaları istendi ve alındı.

\section{Verilerin Toplanması}

Boy ve Kilo Ölçümü: Sporcuların boy uzunlukları $\pm 1 \mathrm{~mm}$ hassasiyetiyle ölçüm yapan bir stadiometre (SECA 213) taşınabilir ayarlı boy ölçer cihaz ile ölçülmüştür. Kişi anatomik duruşta iken insprasyon aşamasında, baş frankfort düzleminde ve baş üstü tablası verteks noktasına değecek şekilde konumlandırılarak, ölçüm çıplak ayak ile santimetre cinsinden alınmıştır.

Sporcuların vücut ağırlıkları, $\pm 0,1 \mathrm{~kg}$ hassasiyetiyle ölçüm yapan vücut analiz (Tanita MC-780 ST) cihazı ile ölçülmüştür. Spor kıyafeti ve (şort ve askılı forma) çıplak ayak ile baskül üzerinde anatomik duruşla iken kilogram cinsinden alınmıştır.

Vücut Kütle İndeksi (VKI):Vücut kütle indeksleri (VKI) kilogram cinsinden ağırlığın, metre cinsinden boyun karesine bölünmesiyle elde edilmiştir $\left(\mathrm{kg} \cdot \mathrm{m}^{-2}\right)$.

\section{Motorik Testler}

Durarak Uzun Atlama Testi: Patlayıcı kuvveti ölçen bu test adım almadan mesafe alabilmek amacıyla en uzağa sıçramayı hedeflemektedir. Katılımcılar ayak parmak uçları uzun atlama çizgisinin gerisinde ve ayaklar bitişik olarak durmuştur. Katılımcı dizlerini bükerek, kollarını geriye ve öne doğru sallayıp, bacaklarını iterek öne doğru mümkün olduğu kadar ileriye atlamıştır ve atladıktan sonra arkaya doğru düşmeden inmeye çalışmıştır. İki defa deneme yapılan testin en iyi derecesi kaydedilmiştir. Başlama çizgisiyle sporcunun bu çizgiye en yakın topuğu arasındaki mesafe ölçülmüştür. İki denemenin en iyisi skor olarak alınır (Kamar, 2008).

El Kavrama Kuvveti: Üst ekstremite kuvvetini değerlendirmek için Takei marka el dinamometresi kullanılarak iki taraflı bir kavrama kuvvet testi yapılmıştır. Katılımcılara, tüm test boyunca ayakta durmak, kollarını düz tutmak ve el dışında dinamometreye vücutlarının herhangi bir bölümü ile dokunmaktan kaçınmaları, dinamometreyi olabildiğince sert bir şekilde kavramaları ve maksimum bir kasılma 
Arı, Y. ve Çolakoğlu, F.F. (2021). Tenis Oyuncularında Core Egzersizleri Tenis Performansını Etkiler Mi? Gaziantep Üniversitesi Spor Bilimleri Dergisi, 6(1), 40-54.

yapmaları istenmiştir.Katılımcılar her bir el ile iki kez (alternatif olarak sağ ve sol) uygulama yapılmıştır (Ulbricht ve ark., 2015).

Flamingo denge testi: Bireylerin statik dengesi flamingo denge aleti ile değerlendirilmiştir. Test sporcunun baskın olan ekstremitesi üzerinde uygulanmıştır. Sporculara testin nasıl uygulanacağı hakkında açıklama yapılmıştır. Sporcuların denge aletinden (15 cm uzunluk ve $4 \mathrm{~cm}$ genişlik) 1 dakika içinde kaç defa düştüğü hesaplanmıştır. Bu süre içinde her düşme sırasında kronometre durdurularak sporcuların tekrardan pozisyon alması beklenmiştir (Tsigilis ve ark., 2002).

Esneklik: Sporcular yere uzun oturur pozisyonda, 90 derece olan ayak bileği ve çıplak ayak tabanları esneklik tahtasına değecek şekilde oturmuşlardır. Gövdeden ileriye doğru eğilip ve dizleri bükmeden, eller vücudunun önünde uzanabildiği yere kadar öne doğru bir şekilde uzanmaları ve uzanabildiği en son noktada 1-2 saniye hareket etmemeleri istenmiştir. Ölçüm yapan kişi sporcuların yanında durmuştur ve dizlerinin bükülmesini engellemiştir. İki defa tekrarlanan testin yüksek olan değeri alınmıştır (Mackenzie, 2005).

Mekik: Sırt üstü yatan sporcunun elleri ense kısmında birleşik, dizler bükülü ve ayak tabanı yerde olacak şekilde teste başlamıştır. Sporcu dirseklerini dizine değene kadar gövdesini yukarıya doğru kaldırmıştır. 30 saniye içerisinde dize temas eden her sayı mekik sayısı adet olarak kabul edilmiştir. Test sırasında ellerini enseden ayırmamaları söylenmiş ve kurallara uygun olmayan tekrarlar sayılmamıştır (Mackenzie, 2005).

\section{Antrenman Programı}

Antrenman programı 8 hafta, haftada $3 \mathrm{kez}$, core egzersiz + teknik antrenman olmak üzere 24 antrenman şeklinde uygulanmıştır. Seçilmiş olan core egzersizleri kolaydan zora doğru istasyon oluşturularak antrenman programına dahil edilmiştir. Core egzersiz programı; 8 hafta boyunca, her hafta 10 egzersiz ve toplamda 80 egzersizden oluşmaktadır. Egzersizler 8 tekrar, tekrar süreleri 5 sn ve 2 set şeklinde uygulanmıştır.

Core egzersiz programı; her hafta 10 egzersiz olmak üzere 8 hafta toplam 80 egzersiz içermektedir. Her egzersiz 8 tekrar, tekrarlar 5 sn, 2 set (setler arası tam dinlenme) olarak yapılmıştır. 
Arı, Y. ve Çolakoğlu, F.F. (2021). Tenis Oyuncularında Core Egzersizleri Tenis Performansını Etkiler Mi? Gaziantep Üniversitesi Spor Bilimleri Dergisi, 6(1), 40-54.

Tablo 1. Uygulanan kor egzersizlerinin açıklamaları (Willardson, 2018).

\begin{tabular}{|c|c|}
\hline $\begin{array}{l}\text { Core } \\
\text { Egzersizleri }\end{array}$ & Açıklamalar \\
\hline Crunch & $\begin{array}{l}\text { Ayak tabanları yere basacak şekilde dizleri bükülü olarak sırt üstü yere uzan. Eller } \\
\text { başın yanında veya arkasında, gövdenin üst kısmı kürek kemikleri yerden kalkana } \\
\text { kadar havaya kalk. }\end{array}$ \\
\hline $\begin{array}{l}\text { Reverse } \\
\text { Crunch }\end{array}$ & $\begin{array}{l}\text { Dizleri bükülü olarak sırt üstü yere uzan. Kollar ve eller göğse yerleştir. Dizler } 90 \\
\text { derecelik açıyla bükülü ve göğüs hizasına kaldır. Bacaklarınızı ve kalçanızı hafifçe } \\
\text { yerden kaldırın. }\end{array}$ \\
\hline Bird Dog & $\begin{array}{l}\text { Quadruped (dört ayak) pozisyonunda, başı dik tut ve omurgayı nötral pozisyonda tut. } \\
\text { Aynı anda sağ bacağınızı ve sol kolunuzu zemine paralel şekilde uzatın. }\end{array}$ \\
\hline Prone Plank & $\begin{array}{l}\text { Ayaklar bitişik, omurga nötral pozisyonda, avuç içleri yere değecek bir şekilde yere } \\
\text { uzan. Vücudu avuç içi ve ayak parmakları üzerinde kaldır. Baş, gövde ve bacakları } \\
\text { düz hizada tutun. }\end{array}$ \\
\hline Superman & $\begin{array}{l}\text { Kollar vücudun önünde uzatılarak yüz üstü uzan. Kollar ve bacaklar aynı anda } \\
\text { yerden kaldır. Bu pozisyonda bir saniye bekledikten sonra kolları ve bacakları } \\
\text { yavaşça indir. }\end{array}$ \\
\hline Leg Lower & $\begin{array}{l}\text { Eller kalçanın altında ya da yanında olacak şekilde ve bacaklar uzatılarak zemine sırt } \\
\text { üstü uzan. Abdominal kasları kontraksyona getirerek bel bölgesini zemine yaklaştır. } \\
\text { Bacaklar yaklaşık } 45 \text { derecellik açıya kadar kalktıktan sonra yavaş yavaş yere indir. }\end{array}$ \\
\hline Sit-Up & $\begin{array}{l}\text { Başlangıç pozisyonda ayaklar zemine temas halinde ve dizler bükülü tut. Eller } \\
\text { göğsün üzerinden omuzlara temas edecek şekilde çaprazla. Harekete omuzları } \\
\text { yerden kaldırmasıyla başla ve oturur pozisyona gelinceye kadar devam et. Ardından } \\
\text { başlangıç pozisyonuna geri dön. }\end{array}$ \\
\hline $\begin{array}{l}\text { Slide Board } \\
\text { Mountain } \\
\text { Climber }\end{array}$ & $\begin{array}{l}\text { Eller bir slide board ekipmanının kenarında veya slide board ekipmanının hemen } \\
\text { dışında, kollar tamamen ekstansiyonda, vücut push-up veya front bridge } \\
\text { pozisyonunda ve ayaklar dorsi fleksiyonda olacak şekilde egzersize başla. Bir diz ve } \\
\text { kalçanın pozisyonu fleksiyonda iken diğer tarafı ekstansiyonda tutun. Fleksiyon } \\
\text { pozisyonunda önceden belirlenmiş bir sürede }(5,10,15,30 \text { saniye) bekle ve daha } \\
\text { sonra başlangıç konumuna dön. Karşı bacakla hareketi tekrarla. }\end{array}$ \\
\hline Jackknife & $\begin{array}{l}\text { Kollar ve bacaklar uzatılarak sırt üstü zemine uzan. Omuzlar ve tek bacak yerden } \\
\text { kaldırılırken hafifçe rotasyon yap. Ters kol ve ters bacak yukarıda birleştir. }\end{array}$ \\
\hline $\begin{array}{l}\text { Plate V-Up } \\
\text { (Ağırlık } \\
\text { kullanmadan) }\end{array}$ & $\begin{array}{l}\text { Her iki elinizde hafif bir plaka veya sağlık topu }(2,3 \text { ila } 4,5 \mathrm{~kg}) \text { tutarak, sırt üstü yere } \\
\text { uzan. Kolları ve bacakları gergin tutarak kalçadan fleksiyon gerçekleştir. Gövdeyi ve } \\
\text { bacakları ortada buluşturmak için zeminden kaldır ve gluteal kasları kullanarak } \\
\text { dengeni sağla. Gövdeyi ve bacakları yavaşça zemine indir. }\end{array}$ \\
\hline
\end{tabular}

\section{Verilerin analizi}

Verilerin istatistiksel analizleri SPSS 18 paket programında yapılmıştır. Çalışmada kullanılan ön-son testten elde edilen her bir değişkendeki veriler normal dağılıma uygunluk için grafiksel yaklaşımlar ve normallik testlerinden örneklemli 'Kolmogorov Smirnov ve Shapiro-Wilk Testi' yapılmıştır. Grupların kendi içinde ön ve son test arasındaki farkları "Paired Sample T Test", gruplar arası karşılaştırmaları "Independent Sample T Test" kullanılmıştır. Bütün istatistiksel yöntemler için yanılma düzeyi 0,05 olarak kabul edilmiştir.

\section{Bulgular}

Araştırmaya katılan sporcuların yaş, boy uzunluğu, vücut ağırığı ve vücut kütle indeks ortalamaları, minimum ve maksimum değerleri tablo 2' de verilmiştir. 
Arı, Y. ve Çolakoğlu, F.F. (2021). Tenis Oyuncularında Core Egzersizleri Tenis Performansını Etkiler Mi? Gaziantep Üniversitesi Spor Bilimleri Dergisi, 6(1), 40-54.

Tablo 2. Sporcuların demografik özellikleri

\begin{tabular}{lcccc}
\hline Değişkenler & Ortalama & Ss & Minimum & Maksimum \\
\hline Yaş (yıl) & 13,9 & 1,08 & 13 & 16 \\
Boy uzunluğu (cm) & 162,69 & 10,31 & 139 & 181 \\
Vücut ağırlığı (kg) & 54,62 & 14,13 & 32,00 & 85,90 \\
Vücut kütle indeksi (kg.m ${ }^{-2}$ ) & 20,36 & 3,54 & 14,41 & 27,73 \\
\hline
\end{tabular}

Tablo 3. Core antrenmanının grup içi ön ve son test değerlerinin karşılaşıııııması

\begin{tabular}{|c|c|c|c|c|c|c|c|c|}
\hline \multirow[b]{2}{*}{ Değişkenler } & \multicolumn{4}{|c|}{ Deney Grubu } & \multicolumn{4}{|c|}{ Kontrol Grubu } \\
\hline & $\begin{array}{c}\text { Antrenman } \\
\text { Öncesi } \\
n=16\end{array}$ & $\begin{array}{c}\text { Antrenman } \\
\text { Sonrası } \\
n=16\end{array}$ & $\mathbf{t}$ & $\mathbf{p}$ & $\begin{array}{c}\text { Antrenman } \\
\text { Öncesi } \\
n=15\end{array}$ & $\begin{array}{c}\text { Antrenman } \\
\text { Sonrası } \\
n=15\end{array}$ & $\mathbf{t}$ & $\mathbf{p}$ \\
\hline $\begin{array}{l}\text { Durarak } \\
\text { Uzun } \\
\text { Atlama } \\
\text { (cm) }\end{array}$ & $172 \pm, 21$ & $188 \pm, 18$ & $-8,735$ &, $000^{\star \star}$ & $154 \pm, 16$ & $154 \pm, 16$ & ,111 & ,913 \\
\hline $\begin{array}{l}\text { Sağ el } \\
\text { kavrama } \\
\text { kuvveti (kg) }\end{array}$ & $29,91 \pm 7,26$ & $34,80 \pm 7,86$ & $-11,807$ &, $000^{\star \star}$ & $25,82 \pm 6,17$ & $28,06 \pm 8,93$ & $-1,918$ & ,076 \\
\hline $\begin{array}{l}\text { Sol el } \\
\text { kavrama } \\
\text { kuvveti (kg) }\end{array}$ & $28,02 \pm 8,04$ & $32,03 \pm 8,06$ & $-11,636$ &, $000^{\star \star}$ & $24,52 \pm 7,15$ & $25,73 \pm 7,63$ & $-1,780$ & ,097 \\
\hline $\begin{array}{l}\begin{array}{l}\text { Flamingo } \\
\text { denge } \\
\text { (adet) }\end{array} \\
\end{array}$ & $12,87 \pm 8,73$ & $7,93 \pm 6,66$ & 6,268 &, $000^{\star \star}$ & $14,80 \pm 6,50$ & $11,80 \pm 3,83$ & 2,717 &, $017^{*}$ \\
\hline $\begin{array}{l}\text { Esneklik } \\
\text { (cm) }\end{array}$ & $18,96 \pm 8,82$ & $23,81 \pm 9,26$ & $-9,541$ &, $000^{\star \star}$ & $14,46 \pm 5,55$ & $15,73 \pm 4,52$ & $-1,669$ & ,117 \\
\hline Mekik (sn) & $27,93 \pm 11,57$ & $34,43 \pm 10,21$ & $-9,874$ &, $000^{\star \star}$ & $23,46 \pm 10,61$ & $24,60 \pm 7,94$ & $-1,186$ & ,255 \\
\hline \multicolumn{9}{|c|}{${ }^{*} p<0,05-{ }^{* \star} p<0,01$} \\
\hline $\begin{array}{l}\text { Çalı } \\
\text { karşıllaştırı } \\
\text { ortalamala } \\
\text { almayan k } \\
\text { göre anlar } \\
\text { son test o } \\
\text { elde edilm }\end{array}$ & $\begin{array}{l}\text { ışmaya katıl } \\
\text { Imasında, c } \\
\text { rına göre ar } \\
\text { ontrol grubu } \\
\text { nlı yüksek } \\
\text { rtalamaları } \\
\text { emiştir ( } p>0\end{array}$ & $\begin{array}{l}\text { an sporcular } \\
\text { ore eğitimi a } \\
\text { lamlı derec } \\
\text { nun son tes } \\
\text { lduğu belirl } \\
\text { in test ortal } \\
\text { 05), (Tablo }\end{array}$ & $\begin{array}{l}\text { In grup } \\
\text { lan de } \\
\text { ede ge } \\
\text { statik } \\
\text { enirken } \\
\text { amaları } \\
\text { 3). }\end{array}$ & $\begin{array}{l}\text { i ön ve } \\
\text { tiği tes } \\
\text { enge } t \\
p<0,0 \\
\text { a göre }\end{array}$ & $\begin{array}{l}\text { e son test n } \\
\text { bunun son } \\
\text { spit edilmiş } \\
\text { test ortalam } \\
\text { 5), diğer m } \\
\text { istatistikse }\end{array}$ & $\begin{array}{l}\text { torik perfo } \\
\text { st ortalam } \\
(p<0,01) \text {. } \\
\text { sı ön test } \\
\text { torik perfo } \\
\text { açıdan anl }\end{array}$ & $\begin{array}{l}\text { rmansla } \\
\text { aları ör } \\
\text { Core e } \\
\text { rtalama } \\
\text { rmansla } \\
\text { amlı fa }\end{array}$ & $\begin{array}{l}\text { arının } \\
\text { test } \\
\text { gitimi } \\
\text { asına } \\
\text { arının } \\
\text { rklılık }\end{array}$ \\
\hline
\end{tabular}


Arı, Y. ve Çolakoğlu, F.F. (2021). Tenis Oyuncularında Core Egzersizleri Tenis Performansını Etkiler Mi? Gaziantep Üniversitesi Spor Bilimleri Dergisi, 6(1), 40-54.

Tablo 4. Core antrenmanının gruplar arası ön ve son test değerlerinin karşılaştırılması

\begin{tabular}{|c|c|c|c|c|c|c|c|c|}
\hline \multirow[b]{2}{*}{ Değişkenler } & \multicolumn{4}{|c|}{ Core Antrenman Öncesi } & \multicolumn{4}{|c|}{ Core Antrenman Sonrası } \\
\hline & $\begin{array}{c}\text { Deney } \\
\text { Grubu } \\
\mathrm{n}=16\end{array}$ & $\begin{array}{c}\text { Kontrol } \\
\text { Grubu } \\
n=15\end{array}$ & $\mathbf{t}$ & $\mathbf{p}$ & $\begin{array}{c}\text { Deney } \\
\text { Grubu } \\
n=16\end{array}$ & $\begin{array}{c}\text { Kontrol } \\
\text { Grubu } \\
n=15\end{array}$ & $\mathbf{t}$ & $\mathbf{p}$ \\
\hline $\begin{array}{l}\text { Durarak } \\
\text { Uzun Atlama } \\
\text { (cm) }\end{array}$ & $172 \pm, 21$ & $154 \pm, 16$ & 2,609 &, $014^{*}$ & $188 \pm, 18$ & $154 \pm, 16$ & 5,253 &, $000 * \star$ \\
\hline $\begin{array}{l}\text { Sağ el } \\
\text { kavrama } \\
\text { kuvveti (kg) }\end{array}$ & $29,91 \pm 7,26$ & $25,82 \pm 6,17$ & 1,690 & ,102 & $34,80 \pm 7,86$ & $28,06 \pm 8,93$ & 2,223 &, $034^{*}$ \\
\hline $\begin{array}{l}\text { Sol el } \\
\text { kavrama } \\
\text { kuvveti }(\mathrm{kg})\end{array}$ & $28,02 \pm 8,04$ & $24,52 \pm 7,15$ & 1,282 &, 210 & $32,03 \pm 8,06$ & $25,73 \pm 7,63$ & 2,234 &, $033^{*}$ \\
\hline $\begin{array}{l}\text { Flamingo } \\
\text { denge (adet) }\end{array}$ & $12,87 \pm 8,73$ & $14,80 \pm 6,50$ &,- 699 & ,490 & $7,93 \pm 6,66$ & $11,80 \pm 3,83$ & $-2,094$ &, $047^{\star}$ \\
\hline $\begin{array}{l}\text { Esneklik } \\
\text { (cm) }\end{array}$ & $18,96 \pm 8,82$ & $14,46 \pm 5,55$ & 1,712 & ,099 & $23,81 \pm 9,26$ & $15,73 \pm 4,52$ & 3,052 &, $005^{\star \star}$ \\
\hline Mekik (sn) & $27,93 \pm 11,57$ & $23,46 \pm 10,61$ & 1,122 & ,271 & $34,43 \pm 10,21$ & $24,60 \pm 7,94$ & 1,122 &, $006^{\star \star}$ \\
\hline
\end{tabular}

Gruplar arası karşılaştırmada, core eğitim öncesi durarak uzun atlama değerinde anlamlı fark olduğu belirlenirken $(p<0,05)$, sağ-sol el kavrama kuvveti, denge, esneklik ve mekik test değerlerinde istatistiksel olarak farklıık gözlenmemiştir $(p>0,05)$. Son test karşılaştırmalarında ise tüm motorik performans testlerinde istatistiksel anlamda farklıık olduğu tespit edilmiştir ( $p<0,05 ; p<0,01)$, (Tablo 4).

\section{Tartışma ve Sonuç}

Tenis birden fazla motorik beceriyi içerdiğinden, tenis sporcularının en üst seviyede sportif performans gösterebilmeleri ve istenilen başarıya ulaşmaları için temel motorik özelliklerinin iyi bir seviyede olması gerekmektedir.

Core, atletik gelişim eğitimi için popüler olmasına rağmen, sportif performans üzerindeki doğrudan etkileri hakkında çok az şey bilinmektedir (Willardson, 2007). Literatürde, sportif performans katkısına yönelik core kuvvet egzersizlerinin bilimsel araştırma sonuçları incelendiğinde performansa etkisi tartışılan bir konudur (Reed ve ark., 2012). Core egzersizleri, bel, karın ve kalça hareketlerinin stabilitesi ve kontrolünü sağlayan 29 farklı kasın antrene edilmesini içeren çalışmalardır ve tüm bu kaslar, vücudun dengede tutulması amacıyla hareket esnasında birlikte çalışırlar (Egesoy ve ark., 2018). Bu nedenle iyi antrene edilmiş olan core bölgenin, 
Arı, Y. ve Çolakoğlu, F.F. (2021). Tenis Oyuncularında Core Egzersizleri Tenis Performansını Etkiler Mi? Gaziantep Üniversitesi Spor Bilimleri Dergisi, 6(1), 40-54.

fonksiyonel atletik performans için, gücün ve hareketlerin aktarımını sağladığı kabul edilmektedir (Sever ve ark., 2017).

Araştırmamızda, core eğitimi alan deney grubunun durarak uzun atlama, sağsol el kavrama kuvveti, flamingo denge, esneklik ve mekik son test ortalamaları ön test ortalamalarına göre anlamlı derecede geliştiği tespit edilmiştir. Core eğitimi almayan kontrol grubunun son test statik denge test ortalaması ön test ortalamasına göre anlamlı yüksek olduğu belirlenirken, diğer motorik performanslarının son test ortalamaları ön test ortalamalarına göre istatistiksel açıdan anlamlı farklılık elde edilmemiştir. Gruplar arası karşılaştırmada ise, core eğitim sonrası, son test tüm motorik performans ortalamalarında anlamlı pozitif azalma ve artışların olduğu tespit edilmiştir. 8 hafta uygulanan core egzersiz programı sonucunda, tenis performans gelişimini olumlu yönde etkilediği görülmektedir.

Reed ve ark. (2012) core antrenmanın sportif performans üzerine yapmış oldukları derleme çalışmasında, literatür sonuçlarına göre core antrenman içeriklerinin birbirinden farklı olduğunu vurgulamışlardır. Aynı zamanda core antrenman uygulanan hedef grubun da birbirlerinden farklı olduğunu belirtmişlerdir. Dolayısıyla temel güç ve stabilitenin atletik performansla bağlantısını tam olarak tanımlamak için daha fazla çalışmanın gerekli olduğunu söylemişlerdir (Reed ve ark., 2012).

Handzel (2003), güçlü bir omurga ve leğen kemiği sonucunda dengede bozulmaların daha az olabileceğini söylemiştir. Aggarwal ve ark. (2010) core stabilitesi ve denge antrenmanı sonucunda, statik denge üzerinde core stabilitesi antrenmanı etkisinin denge antrenmanına oranla daha büyük olduğunu belirtmişlerdir. Yapılan başka bir çalışmada, bosu topu kullanılarak 4 hafta uygulanan antrenman sonrasında, deney grubunun statik denge kabiliyetinde anlamlı bir fark gözlemlenmiştir (Yaggie ve Campbell, 2006). Sandrey ve Mitzel (2013), Kahle ve Gribble (2009) altı haftalık bir core stabilizasyon eğitim programından sonra dengede önemli bir iyileşme olduğunu bildirmişlerdir. Benzer başka bir çalışmada, 8 haftalık core egzersiz programının, üniversite sporcularının statik denge performanslarında anlamlı farklılık tespit etmişlerdir (Hung ve ark., 2019). Bashir ve ark (2019), 5 haftalık core eğitimi sonrasında genç tenis oyuncularında dinamik denge performansında iyileşme olduğunu vurgulamışlardır. Tenis oyuncularına uygulanan bir başka çalışmada 8 haftalık core antrenman sonrasında, grupların statik denge son testleri arasında istatistiksel anlamda farklılık olduğunu söylemişlerdir (Eren, 2019). Ayrıca 
Arı, Y. ve Çolakoğlu, F.F. (2021). Tenis Oyuncularında Core Egzersizleri Tenis Performansını Etkiler Mi? Gaziantep Üniversitesi Spor Bilimleri Dergisi, 6(1), 40-54.

diğer yapılan çalışmalar, farklı türde yapılan core eğitimi sonrasında statik ve dinamik denge gelişiminde pozitif ilerleme görüldüğünü bildirmişlerdir (Cosio-Lima ve ark., 2003; Basset ve Leach, 2011; Granacher ve ark., 2014). Core stabilite fiziksel aktiviteyi, dengeyi ve dolayısıyla performansı iyileştirmede önemlidir (Bashir ve ark., 2019). Elde ettiğimiz çalışma sonucu literatür ile paralellik göstermektedir.

Tenis oyununun fiziksel talebi değişir, oyuncular oyun içerisinde yön değiştirmeler, sıçramalar ve vücutlarını kaydırırlar. Bu çalışma sonucunda deney grubunun tenis performanslarında (durarak uzun atlama, esneklik, el kavrama kuvveti ve mekik) olumlu yönde gelişme olduğu görülmüştür. Çalışmamızın bulguları, core eğitimin sağlıklı ve atletik bir popülasyon üzerindeki etkisini araştıran bazı çalışmaların bulgularıyla tutarlıdır (Özdoğru, 2018; Chaurasiya ve Mehta, 2018; Kaçar, 2019). Afyon (2019) 8 haftalık core egzersizlerinin futbolcuların sağ pençe kuvvetlerinde istatistiksel anlamda gelişme olduğunu tespit etmişlerdir. Ayrıca Ahn ve ark. (2018) boks sporcularına 8 hafta core egzersizi uygulamışlar ve sporcuların pençe kuvvet performanslarında pozitif yönde artış olduğunu bulmuşlardır. Başka bir çalışmada, genç sporculara uygulanan 10 haftalık core egzersizlerinin durarak uzun atlama performansları üzerinde anlamlı gelişme elde etmişlerdir (Baş, 2018). Taşkın (2016) kadın futbolcularda uygulanan 8 haftalık core egzersiz programının durarak uzun atlama performanslarında anlamlı gelişme olduğunu vurgulamışlardır. Bu bulgulara ek olarak, core egzersizinin esneklik performansları üzerinde de olumlu etkisi olduğunu bildiren çalışmalar mevcuttur (Özdoğru, 2018; Karacaoğlu, 2015). Axel ve ark (2018), 8 haftalık core güç antrenmanı uygulamasının atletik performans ölçümlerini geliştirdiği sonucuna varmışlardır. Sato ve Mokha (2009) ise core güç antrenmanının koşucularda performansı artırmak için etkili bir antrenman olabileceğini söylemişlerdir. Aynı zamanda Patil ve ark. (2014), core kas güçlendirmenin, 50 metrelik serbest stil sprint süresi, hız ve inme endeksinde önemli iyileşmeler olarak öngörülen genç rekabetçi yüzücülerin performansını artırdığını vurgulamışlardır. Filipa ve ark (2010), kadın futbolcuların nöromüsküler antrenman sonrasında gelişmiş bir core stabilite sergilediğini göstermişlerdir. Ayrıca literatür incelendiğinde daha fazla core gücünün atletik performansı geliştirip geliştirmediğine dair çelişkili kanıtlar da bulunmaktadır (Tse ve ark. 2005; Sato ve Mokha, 2009; Nesser ve ark., 2008). Atletik performansın iyileştirilmesinde core eğitimin rolü için karışık sonuçlar gösterse de, araştırmalar güçlü bir core bölgenin çeşitli atletik 
Arı, Y. ve Çolakoğlu, F.F. (2021). Tenis Oyuncularında Core Egzersizleri Tenis Performansını Etkiler Mi? Gaziantep Üniversitesi Spor Bilimleri Dergisi, 6(1), 40-54.

hareketlerin performansı için gerekli bir temel sağladığını vurgulamışlardır (Reed ve ark., 2012).

Sonuç olarak; tenis oyuncularına uygulanan core egzersiz programlarının tenis performansları üzerinde olumlu etkileri olduğu tespit edilmiştir. Ayrıca farklı şekilde tasarlanmış core antrenmanlarının, farklı yaş gruplarında alt ve üst ekstremitelerine yönelik olası sakatlıkların önlenmesi ve motor performans üzerindeki etkisini ortaya koyacak yeni araştırmaların ilgili literatüre katkı sağlayacağı öngörülmektedir.

\section{Kaynaklar}

Afyon, Y. A. (2019). The effect of core training on some motoric features of university footballers. Journal of Education and Training Studies, 7(3), 79-85.

Aggarwal, A., Zutshi, K., Munjal, J., Kumar, S., ve Sharma, V. (2010). Comparing stabilization training with balance training in recreationally active individuals. International Journal of Therapy and Rehabilitation, 17(5), 244-253.

Ahn, S.-H., Lee, J.-S., \& Kim, C.G. (2018). The effect of core training on fitness, trunk isokinetic muscular function, and body-composition in boxing athletes. The Asian Journal of Kinesiology, 20(4), 22-29.

Akuthota, V., ve Nadler, S.F. (2004). Core strengthening. Archive Physical Medicine and Rehabilitation, 85(1), 86-92.

Axel, T.A., Crussemeyer, J.A., Dean, K., ve Young, D.E. (2018). Field test performance of junior competitive surf athletes following a core strength training program. International Journal of Exercise Science, 11(6), 696-707.

Bashir, S.F., Nuhmani, S., Dhall, R., ve Muaidi, Q.I. (2019). Effect of core training on dynamic balance and agility among Indian junior tenis players. Journal of Back and Musculoskeletal Rehabilitation, 32(2), 245-252.

Basset, S., ve Leach, L.L. (2011). The effect of an eight-week training programme on core stability in junior female elite gymnasts. African Journal for Physical Health Education, Recreation and Dance, 17(3), 9-19.

Baş, M. (2018). 11-13 yaş grubu futbolculara uygulanan 10 haftalık core antrenmanın seçili motor parametrelere etkisinin değerlendirilmesi. İstanbul Gelişim Üniversitesi Sağlık Bilimleri Enstitüsü.

Bompa, T. O., Pasqual, M., \& Cornacchia, L. (2014). Nitelikli kuvvet antrenmanı. Bağırgan, T Çev.), Spor Yayınevi ve Kitabevi, Ankara, 69-70. 
Arı, Y. ve Çolakoğlu, F.F. (2021). Tenis Oyuncularında Core Egzersizleri Tenis Performansını Etkiler Mi? Gaziantep Üniversitesi Spor Bilimleri Dergisi, 6(1), 40-54.

Chaurasiya, M., \& Mehta, D. (2018). Effect of core stability exercises in enhancing the upper and lower body strength of women cricket players. International Journal of Yogic, Human Movement and Sports Sciences, 3(2), 248-250.

Cosio-Lima, L.M., Reynolds, K.L., Winter, C., ve Paolone, V. (2003). Effects of physio ball and conventional flor exercises on early phase adaptations in back and abdominal core stability and balance in women. The Journal of Strength and Conditioning Research, 17(4), 721-725.

Egesoy, H., Alptekin, A., ve Yapıcı, A. (2018). Core exercises in sports. International Journal of Contemporary Educational Studies, 4(1), 10-21.

Eren, E. (2019). 12-14 yaş grubu tenisçilerde 8 haftalık core antrenmanın yer vuruş hızlarına ve bazı motorik özelliklere etkisinin incelenmesi. Yüksek Lisans Tezi, Bartın Üniversitesi, Sosyal Bilimler Enstitüsü.

Fernandez-Fernandez, J., Ellenbecker, T., Sanz-Rivas, D., Ulbricht, A., ve Ferrauti, A. (2013). Effects of a 6-week junior tennis conditioning program on service velocity. Journal of Sports Science and Medicine, 12(2), 232-239.

Fig, G. (2005). Strength training for swimmers: training the core. Strength and Conditioning Journal, 27(2), 40-42.

Filipa, A., Byrnes, R., Paterno, M.V., Meyer, G.D., ve Hewett, T.E. (2010). Neuromuscular training improves performance on the star excursion balance test in young female athletes. Journal of Orthopedic Sports Physical Therapy, 40(9), 551-558.

Gelen, E., Mengütay, S., ve Karahan, M. (2009). Analysing physical fitness and biomechanical factors that determine tennis serve performance. Uluslararası İnsan Bilimleri Dergisi, 6(2), 666-682.

Gür, F., ve Ersöz, G. (2017). Evaluation of the effects of core training on the core strength, static and dynamic balance characteristics of tennis athletes in the 814 age group. Spormetre Beden Eğitimi ve Spor Bilimleri Dergisi, 15(3), 129138.

Granacher, U., Schellbach, J., Klein, K., Prieske, O., Baeyens, J.P., ve Muehlbauer, T. (2014). Effects of core strength training using stable versus unstable surfaces on physical fitness in adolescents: a randomized controlled trial. BMC Sports Science, Medicine and Rehabilitation, 6(1), 40.

Handzel, T.M. (2003). Core training for improved performance. NSCA's Performance Training Journal, 2(6), 26-30. 
Hung, K. C., Chung, H. W., Yu, C. C. W., Lai, H. C., \& Sun, F. H. (2019). Effects of 8week core training on core endurance and running economy. Plos One, 14(3), e0213158.

Kaçar, M. R. (2019). 8 haftalık su üzerinde core antrenmanın programının bayan basketbolcuların denge ve kuvvet parametreleri üzerine etkisinin incelenmesi. İstanbul Gelişim Üniversitesi Sağlık Bilimleri Enstitüsü.

Kahle, N.L., ve Gribble, P.A. (2009). Core stability training in dynamic balance testing among young, healthy adults. Athletic Training and Sports Health Care. 1(2), 65-73.

Kamar, A. (2008). Sporda yetenek beceri ve performans testleri. Ankara: Nobel Yayınları.

Karacaoğlu, S. (2015). Erkek voleybolcularda core antrenmanın fiziksel uygunluk özelliklerine etkisi. Yüksek Lisans Tezi Mehmet Akif Ersoy Üniversitesi, Burdur.

Kermen, O. (2002). Tenis: teknik ve taktikleri: Nobel Akademik Yayıncılık.

Kilit, B., ve Arslan, E. (2017). Tenis müsabakalarında fizyolojik gereksinimler. Spormetre Beden Eğitimi ve Spor Bilimleri Dergisi, 15(3), 157-164.

Leetun, D.T., Ireland, M.L., Willson, J.D., Ballantyne, B.T., ve Davis, I.M. (2004). Core stability measures as risk factors for lower extremity injury in athletes. Medicine and Science in Sports and Exercise, 36(6), 926-934.

Lloyd, R. S., Read, P., Oliver, J. L., Meyers, R. W., Nimphius, S., \& Jeffreys, I. (2013). Considerations for the development of agility during childhood and adolescence. Strength \& Conditioning Journal, 35(3), 2-11.

Mackenzie, B. (2005). 101 Performance evaluation tests. Electric Word plc, London.

McGill, S.M., Grenier, S., Kavcic, N., ve Cholewicki, J. (2003). Coordination of muscle activity to assure stability of the lumbar spine. Journal of Electromyography and Kinesiology, 13, 353-359. http://doi.org/10.1016/S1050-6411(03)00043-9

Nesser, T.W., Huxel, K.C., Tincher, J.L., ve Okada, T. (2008). The relationship between core stability and performance in division I football players. Journal of Strength and Conditioning Research, 22(6), 1750-1754.

Özdoğru, K. (2018). 10-12 Yaş grubu erkek yüzücülerde 8 haftalık dinamik kor antrenmanının bazı motorik özellikler ile $100 \mathrm{~m}$ karışık stil yüzme performansına etkisi. İstanbul Gelişim Üniversitesi Sağlık Bilimleri Enstitüsü. 
Panjabi, M.M. (1992). The stabilizing system of the spine. part I. function, dysfunction, adaptation, and enhancement. Journal of Spinal Disorders, 5(4), 383-389. http://doi.org/10.1097/00002517-199212000-00001

Patil, D., Salian, S.C., ve Yardi, S. (2014). The effect of core strengthening on performance of young competitive swimmers. International Journal of Science and Research (IJSR), 3(6), 2470-2477.

Pluim, B.M., Miller, S., Dines, D., Renstrom, P.A., Windler, G., Norris, B., Stroia, K., Donaldson, A., ve Martin, K. (2007). Sport science and medicine in tennis. British Journal of Sports Medicine, 41(11), 703-704.

Reed, C.A., Ford, K.R., Myer, G.D., ve Hewett, T.E. (2012). The effects of isolated and integrated "core stability" training on athletic performance measures: $A$ systematic review. Sports Medicine, 42(8), 697-706.

Reid, M., Quinn, A., \& Crespo, M. (2003). Strength and conditioning for tennis. International Tennis Federation.

Samson, K.M. (2005) The effects of a five-week core stabilization-training program on dynamic balance in tenis athletes, Master of Science in Athletic Training, West Virginia University.

Samson, K., Sandrey, M., ve Hetrick, A. (2007). A core stabilization training program for tennis athletes. Human Kinetics, 12(3), 41-46.

Sandrey, M.A., ve Mitzel, J.G. (2013). Improvement in dynamic balance and core endurance after a 6-week core-stability-training program in high school track and field athletes. Journal of Sport Rehabilitation, 22(4), 264-271.

Sato, K., ve Mokha, M. (2009). Does core strength training in fluence running kinetics, lower-extremity stability, and 5000-M performance in runners? The Journal of Strength and Conditioning Research, 23(1), 133-140.

Sever, O., Kır, R., ve Yaman, M. (2017). The impact of periodized core training program on accurate service velocity of male tenis players aged 11-13. Journal of Human Sciences, 14(3), 3022-3030. doi:10.14687/jhs.v14i3.4760.

Stephenson, J., ve Swank, A.M. (2004). Core training: Designing a program for anyone. Strength and Conditioning Journal, 26(6), 34-37.

Taskin, C. (2016). Effect of core training program on physical functional performance in female soccer players. International Education Studies, 9(5), 115-123. 
Arı, Y. ve Çolakoğlu, F.F. (2021). Tenis Oyuncularında Core Egzersizleri Tenis Performansını Etkiler Mi? Gaziantep Üniversitesi Spor Bilimleri Dergisi, 6(1), 40-54.

Tse, M.A., McManus, A.M., ve Masters, R.S. (2005). Development and validation of a core endurance intervention program: İmplications for performance in collegeage rowers. Journal of Strength and Conditioning Research, 19(3), 547-552.

Tsigilis, N., Doud, H., ve Tokmakidis, S.P. (2002). Test-retest reliability of the eurofit test battery administered to university students. Perceptual and Motor Skills, 95, 1295-300.

Ulbricht, A., Fernandez-Fernandez, J., Mendez-Villanueva, A., ve Ferrauti, A. (2015). The relative age effect and physical fitness characteristics in german male tennis players. Journal of Sports Science and Medicine, 14, 634-642.

Urhausen, A., \& Kindermann, W. (2002). Diagnosis of overtraining. Sports Medicine, 32(2), 95-102.

Weston, M., Hibbs, A.E., Thompson, K.G., ve Spears, I.R. (2015). Isolated core training improves sprint performance in national-level junior swimmers. International Journal of Sports Physiology and Performance, 10, 204-210. http://dx.doi.org/10.1123/ijspp.2013-0488.

Willardson, J. M. (2018). Core gelişimi. (Ç. Bulgan ve M. A. Başar, Çev.) 1st ed. İstanbul: İstanbul Tıp Kitabevleri.

Willardson, J.M. (2007). Core stability training: applications to sports conditioning programs. Journal of Strength and Conditioning Research, 21(3), 979-985.

Wilson, E. (2005). Core stability: Assessment and functional strengthening of the hip abductors. Strength and Conditioning Journal, 27(2), 21-23.

Yaggie, J.A., ve Campbell, B.M. (2006). Effects of balance training on selected skills. The Journal of Strength and Conditioning Research, 20(2), 422-428. 